\title{
A Trade-Off between the Efficiency, Ripple and Volume of a DC-DC Converter
}

\author{
Mohsen Taherbaneh ${ }^{\dagger}$, Amir H. Rezaie*, Hasan Ghafoorifard*, Maddad Mirsamadi*, and Mohammad B. Menhaj* \\ $\dagger$ Dept. of Electrical and Information Technology, IROST, Tehran, Iran \\ * Dept. of Electrical Engineering, Amirkabir University of Technology, Tehran, Iran
}

\begin{abstract}
In space qualified DC-DC converters, optimization of the following electrical characteristics is of greater interest in comparison with other specifications; power loss/efficiency, output voltage ripple and volume/weight. The main goal of this paper is to present an appropriate solution for optimizing the above mentioned characteristics. For this purpose, a comprehensive power loss model of a DC-DC converter is fully developed. Proper models are also demonstrated for assessment of the output voltage ripple and the utilized transformer volume as the bulkiest component in a DC-DC converter. In order to provide a test bed for evaluation of the proposed models, a 50W push-pull DC-DC converter is designed and implemented. Finally, a novel cost function with three assigned weight functions is proposed in order to have a trade-off among the power loss, the output voltage ripple and the utilized transformer volume of the converter. The cost function is optimized for applications in which volume has the highest priority in comparison with power loss and ripple. The optimization results show that the transformer volume can be decreased by up to $51 \%$ and this result is verified by experimental results. The developed models and algorithms in this paper can be used for other DC-DC converter topologies with some minor modifications.
\end{abstract}

Key Words: DC-DC converter, Optimum switching frequency, Output voltage ripple, Power loss, Volume

\section{INTRODUCTION}

The design of power converter units for satellites is greatly influenced by the existing limitations in space applications. These limitations include limited available electric power (usually generated by a photovoltaic system,) as well as limited volume and weight allocated for the power management subsystem. Any increase in the required electric power or in the weight or size of a satellite would considerably increase the satellite's launch expenses. Thus, the designer of a DCDC converter for space systems usually faces two important requirements: high efficiency, and small weight and size.

The switching frequency of a converter is a parameter that does not allow the above requirements to be satisfied simultaneously. Instead it makes trade-offs between them. A higher switching frequency allows smaller and lighter components to be used, but in return it adds to the internal losses of the converter and hence reduces efficiency. On the other hand, the output voltage ripple of a DC-DC converter is directly influenced by the switching frequency, and so it is a third parameter that must be considered when designing the converter. Therefore, there should be an optimum switching frequency, which above all other requirements, must be satisfied effectively. Finding this optimum frequency for any

\footnotetext{
Manuscript received Jul. 26, 2010; revised Jun. 12, 2011

Recommended for publication by Associate Editor Byung-Cho Choi.

$\dagger$ Corresponding Author: m.taherbaneh@irost.org

Tel: +98-228-227-6311, Fax: +98-228-227-6620, IROST, Iran

* Dept. of Electrical Eng., Amirkabir Univ. of Technology, Iran
}

given condition of the converter (load current, input voltage, etc.) is the main goal of this paper. In order to find this optimum frequency, first the effects of the switching frequency on the efficiency, size and weight, and output ripple of the converter must be quantified. Therefore, the different causes of loss in a DC-DC converter need to be scrutinized and mathematical expressions for each type need to be derived. Moreover, equations that relate the output ripple as well as the size and weight of a converter to its switching frequency need to be found. In the following, several relevant published papers are reviewed. A comparative study, which considers a trade-off between the reactive components and the volume of the heat sink for two $6 \mathrm{~kW}$ converters, one using ZVS/ZCS and the other using a more conventional circuit with hard switching, has been done in [1]. The results of this study indicate that the minimum volume may actually occur below $20 \mathrm{kHz}$. It also appears that the ZVS/ZCS has a considerable size advantage over the more conventional IGBT circuits. Koalr and others investigated the dependence of the volume of the cooling system and the main passive components for basic forms of power electronics energy conversion on the switching frequency and determined that the switching frequencies minimize the total volume [2]. A trade-off between the switching frequency of an ADSL power supply versus the ripple, size, and efficiency, while maintaining a constant modem throughput has been presented in [3]. Within the optimum frequency range, losses are minimized and the power supply efficiency is near its maximum level. However, the volume is increased due to the 
additional filtering required to maintain an acceptable modem throughput. A portable fuel-to-electrical energy converter that can be carried on the body, is able to supply an average of $20 \mathrm{~W}$ for 4 days and has a total weight of less than $4 \mathrm{~kg}$ has been proposed in [4]. Due to the limited total weight of the system, each part of the system must have the highest possible efficiency to weight ratio. The optimization of a synchronous buck DC-DC converter that is used to regulate a variable power source to a constant output voltage for a load has also been proposed. An auto-tuning adaptive digital controller with maximum efficiency point tracking to optimize a DCDC converter's switching frequency has been presented in [5]. The adaptive-frequency-optimization (AFO) controller adjusts the DC-DC converter's switching frequency while tracking the converter's minimum input power (maximum efficiency) point under variable operation conditions of the power converter. A design methodology to define the input current ripple and the switching frequency required to minimize the volume of filters and heat sinks using different methods to reduce the switching losses has been described in [6]. An increase of the switching frequency reduced the boost inductor volume, but required a bulky EMI filter to operate according to the required standards. Higher frequencies also intensified the switching losses in the semiconductor devices, which results in an increase in the heat sink's volume. In the same way, a higher current ripple demanded a lower boost inductor volume, but it also required a bulky EMI filter and intensified the conduction losses. A design procedure for the optimization of ferrite high frequency power transformers has been presented in [7]. The product of the power loss, the cross section of the core and the winding area has been chosen as an optimization index, along with the average surface temperature increase as a constraint.

There are many papers in the literature investigating the power loss analysis of DC-DC converters and their main components separately. Efficiency estimation of different DCDC converter topologies has been discussed briefly in [8]. A mathematical tool for the calculation of MOSFET power losses using data-sheet parameters has been developed in [9]. The turn-off process of synchronous rectifier MOSFETs has been analyzed and a simple model has been introduced for the calculation of power losses in order to optimize system efficiency in [10]. A study of the steady-state power loss in the output diode of a flyback switching DC-DC converter has been reported in [11]. An analytical method for approximating the turn-off loss of an ideal diode has been described in [12]. A new model for accurate estimation of iron powder core loss has been proposed in [13], which will be referred to as the Oliver model. This model has been verified by experimental data. In [14], basic formulas for determining the approximate inductor power losses have been derived. The estimation of inductor losses using readily available data from core and inductor suppliers along with the relevant power supply application parameters has been discussed in [15]. General techniques for calculating and predicting power loss in each component of a switched-mode power supply have been proposed in [16]. A very simple and quick method for calculating the total switching loss of a converter has been presented in [17]. It is clear that in space applications, no heat sinks can be used due to the lack of air convection. As a result, the only way to cool a system or a utilized device is through heat conduction and radiation. As mentioned earlier, most of research that has been done is for the optimization of commercial DC-DC converters. However, in this paper DC-DC converters that can be used in space applications will be dealt with.

Hence, the rest of this paper is organized as follows. In section II, all of the different causes of loss in a DCDC converter will be discussed in detail, and mathematical expressions for each type of loss will be found, most of which will have the switching frequency present. This will help predict the efficiency of the converter at different switching frequencies for any load or line condition. In section III, the relationship between the weight and size of a converter and its switching frequency will be examined. This will lead to an estimation of the minimum size or weight needed for a given switching frequency. In section IV, the dependence of the output voltage ripple on the switching frequency will be explained. The introduced equations will help determine the range of frequencies that do not let the output ripple exceed the maximum ripple specifications. In section V, the test bed which was built in order to collect experimental data will be described. Detailed specifications of the implemented pushpull converter are provided, and the design considerations are described. Having gathered all of the theoretical relationships needed, the different parameters of a DC-DC converter will be modeled and simulated in MATLAB, in section VI. It will then be possible to examine the different characteristics of a converter (efficiency, weight and size, output ripple, etc.) for any given switching frequency. In section VII, the information gathered in the previous chapters will be used in order to calculate the optimum switching frequency for the converter. Different illustrations are provided which suggest the optimum frequency for different load and line conditions. Finally in section VIII, the conclusions drawn from the research are explained and different suggestions are provided for future research.

\section{LOSSES IN A DC-DC CONVERTER}

Generally in a DC-DC converter the losses can be categorized into two main groups: conduction losses and switching losses. Predicting the efficiency of the converter requires precise examination of all these causes of power loss. A power loss analysis for a push-pull DC-DC converter has been fully developed in [18]. Hence, in this section, the equations that model the losses for a push-pull DC-DC converter will be indicated briefly. The general voltage and current waveforms of the converter are illustrated in Fig. 1 [18].

\section{A. MOSFET Conduction Loss}

The MOSFETs used in DC-DC converters are not ideal switches. In the on state, they exhibit some resistance between the drain and source terminals. However, it is very small due to the aid of modern semiconductor technologies. The current passing through this resistance while the MOSFET is on causes power loss. Considering the trapezoidal current 
waveforms passing through the switches in a push-pull converter, as shown in Fig. 1, the conduction loss associated with each switch can be calculated as follows:

$$
\begin{aligned}
P_{M O S-C o n} & =\frac{1}{T} \int_{0}^{T} R_{D S o n} I_{s w}^{2}(t) d t \\
& =R_{D S o n}\left(\frac{I_{p}^{2}+I_{m}^{2}+I_{p} I_{m}}{3}\right) \times\left(\frac{T_{o n}}{T}\right) .
\end{aligned}
$$

The on-time of the switches is set by a PWM generator to get the desired output voltage [8]:

$$
V_{\text {out }}=\frac{2 T_{\text {on }}}{T} \frac{N_{s}}{N_{p}} V_{\text {in }}
$$

The input current passing through the switches is a reflection of the secondary currents in the primary of the transformer plus the magnetizing current [8]. Equations (3) and (4) indicate the relationships between the mentioned currents in Fig. 1.

$$
\begin{gathered}
I_{M}=\frac{N_{s}}{N_{p}} I_{1} \\
I_{P}=\frac{N_{s}}{N_{p}} I_{2}+I_{\text {magnetizing }} \\
=\frac{N_{s}}{N_{p}} I_{2}+\frac{V_{\text {in }}}{L_{m}} T_{\text {on }}=\frac{N_{s}}{N_{p}} I_{2}+\frac{V_{\text {out }}}{2 L_{m} f}\left(\frac{N_{p}}{N_{s}}\right) .
\end{gathered}
$$

The average of $I_{1}$ and $I_{2}$ makes the load current $\left(I_{1}+I_{2}=\right.$ $2 I_{\text {Load }}$ ), and their difference, $I_{2}-I_{1}$, (the current ripple) is inversely proportional to the output inductance:

$$
\frac{I_{2}-I_{1}}{T / 2-T_{\text {on }}}=\frac{V_{\text {out }}}{L}=\text { slope of falling inductor current. }
$$

Substituting in (2) the following is obtained:

$$
\begin{aligned}
& I_{1}=I_{\text {Load }}-\frac{V_{\text {out }}}{4 L f}\left[1-\left(\frac{V_{\text {out }}}{V_{\text {in }}}\right)\left(\frac{N_{p}}{N_{s}}\right)\right] \\
& I_{2}=I_{\text {Load }}+\frac{V_{\text {out }}}{4 L f}\left[1-\left(\frac{V_{\text {out }}}{V_{\text {in }}}\right)\left(\frac{N_{p}}{N_{s}}\right)\right] .
\end{aligned}
$$

During the dead-time interval, the current commutates from the MOSFET channel to the MOSFET body diode. The calculation of the diode power loss can be done by using the following parameters: the forward voltage drop of the body diode $U_{D 0}$, the source of the drain body diode current $I_{S D}$, the body diode on the time $t_{D}$ and the converter switching frequency $f$ :

$$
P_{\text {Diode }}=U_{D 0} \cdot I_{S D} \cdot t_{D} \cdot f .
$$

All of the parameters required to define the MOSFET body diode conduction loss can be obtained from the diagrams in a MOSFET datasheet. The value of $R_{D S o n}$ is temperature dependent, and increases as the temperature rises. This creates a positive-feedback mechanism which will result in excessive power loss in the MOSFETs. Thus, using an appropriate cooling system for the MOSFETs will help to control the conduction losses in the MOSFETs.
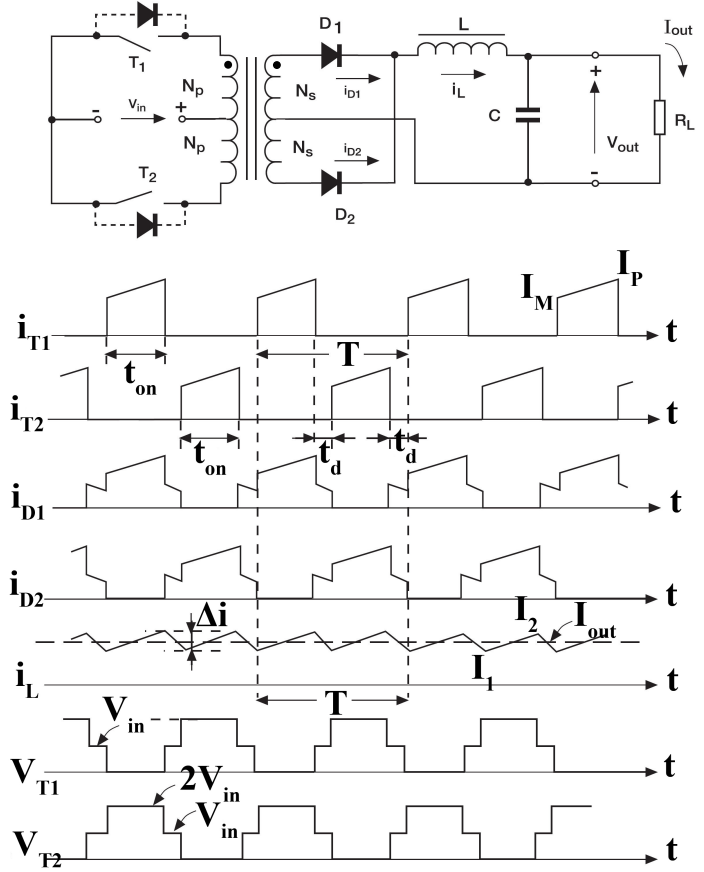

Fig. 1. push-pull converter current and voltage waveforms

\section{B. MOSFET Switching Loss}

Extensive work has been done on the estimation of MOSFET switching loss [9],[19],[20] and [21]. For a rough estimation of the power loss, a linear approximation of the MOSFET switching process is sufficient and presents the worst case scenario calculation [9]. The model provided in [9] is an adequately precise model which will be used here as the basis for calculations. Fig. 2 shows the MOSFET voltage and current waveforms during the on and off transitions [18].

The worst case turn-on energy losses in a power MOSFET $\left(E_{\text {onM }}\right)$ can be calculated as the sum of the switch-on energy without taking the reverse-recovery process into account and the switch-on energy caused by the reverse-recovery of the free-wheeling diode:

$$
E_{o n M}=U_{D D} \cdot I_{D o n} \cdot \frac{t r i+t f u}{2}+Q_{r r-M o s} \cdot U_{D D} .
$$

The turn-on energy in the diode consists mostly of the reverse-recovery energy $\left(E_{\text {onD }}\right)$ :

$$
E_{\text {onD }}=\frac{1}{4} \cdot Q_{r r-M o s} \cdot U_{D r r} .
$$

where $U_{D D}$ and $U_{D r r}$ are the input voltage and the voltage across the diode during reverse recovery respectively. For the worst case calculation $U_{D r r}$ can be approximated with the input voltage $\left(U_{D D}=U_{D r r}\right)$. The switch-off energy loss in the MOSFET can be calculated in a similar manner. The switch-off losses in the diode are often neglected $\left(E_{o f f D}=0\right)$. Therefore:

$$
E_{o f f M}=U_{D D} \cdot I_{D o f f} \cdot \frac{t r u+t f i}{2} .
$$

The switching loss in the MOSFET and the diode are the product of the switching energy and the switching frequency $(f)$ :

$$
P_{s w M}=\left(E_{o n M}+E_{o f f M}\right) \cdot f
$$




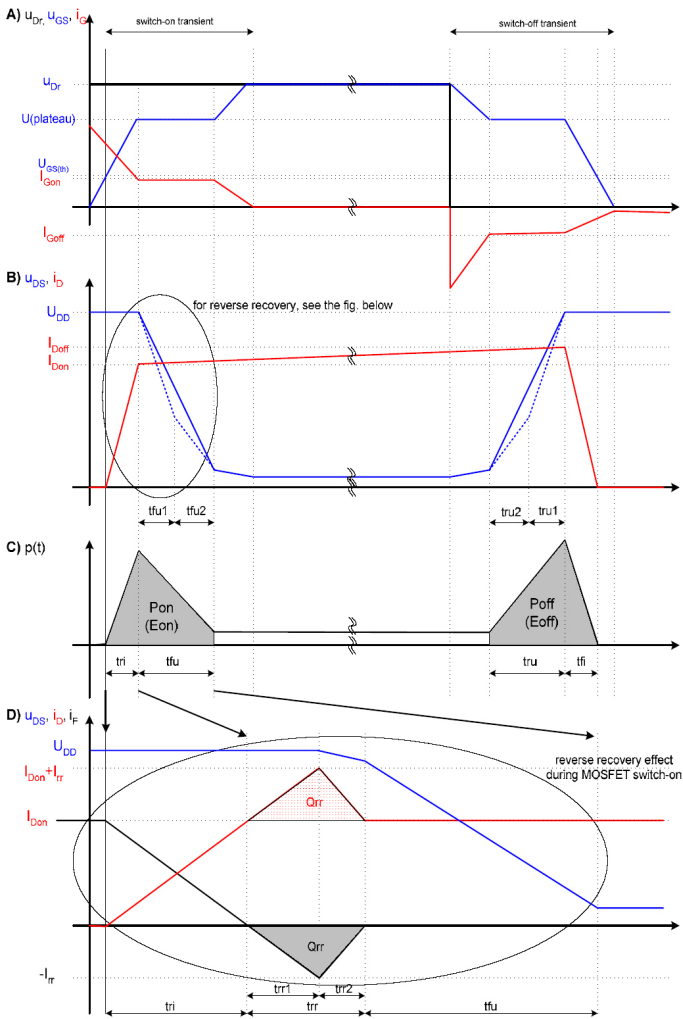

Fig. 2. Switching transients of the power MOSFET.

$$
P_{s w D}=\left(E_{o n D}+E_{o f f D}\right) \cdot f \approx E_{o n D} \cdot f .
$$

Using this information we can calculate the MOSFET switching loss precisely.

\section{Output Rectifier Conduction Loss}

The forward voltage drop across the rectifier or the freewheel diodes in a DC-DC converter is a cause of power loss in the circuit. In a push-pull converter, the same set of diodes takes on the roles of both rectification and freewheeling. Assuming the voltage drop across the diode to be $V_{F}$, we can calculate the power loss in each diode.

$$
\begin{aligned}
P_{\text {diode-con }} & =\frac{1}{T} \int_{0}^{T} V_{F} I_{D}(t) d t \\
& =V_{F} \frac{I_{1}+I_{2}}{4}=\frac{1}{2} V_{F} I_{\text {Load }} .
\end{aligned}
$$

This is a rather large power loss which has a considerable influence on the converter efficiency, particularly under heavy loads. Using synchronous rectifiers instead of diode rectifiers is a way to battle this large power loss. However, in this paper, a diode is chosen as an output rectifier.

\section{Output Rectifier Switching Loss}

The reverse recovery current can be approximated by a triangle as shown in Fig. 3. As observed in the figure, the reverse recovery time $\left(t_{r r}\right)$ consists of two intervals $t_{s}$ and $t_{f}$. The power loss associated with the diode's turn-off actually occurs during $t_{f}$, because the voltage across the diode is reversed during this period.

The reverse recovery charge, $Q_{r r}$, is equal to the total area under the triangle and is given by (15).

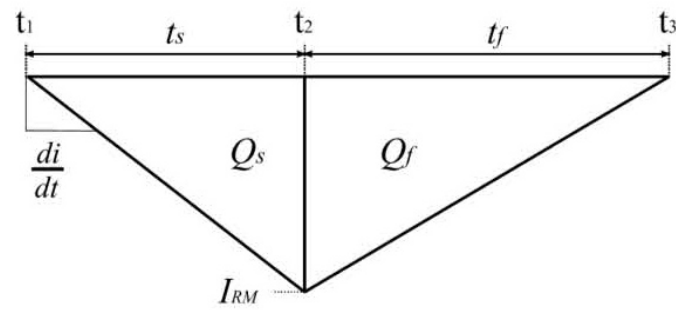

Fig. 3. Approximation of reverse recovery current.

$$
Q_{r r}=Q_{s}+Q_{f}
$$

The softness factor, normally provided by the manufacturer, makes a relationship between $Q_{r r}, I_{R M}$ and $d i / d t$ as follows:

$$
s=\frac{Q_{r r}}{Q_{s}}-1=\frac{Q_{r r}}{0.5 I_{R M}^{2} /(d i / d t)}-1 \Rightarrow Q_{f}=Q_{r r}\left(\frac{s}{s+1}\right) .
$$

The turn-off power loss in the diode due to its reverse recovery current characteristic can be calculated by:

$$
P_{D-s w}=t_{f} \cdot I_{R M} \cdot V_{R} \cdot f=V_{R} \cdot Q_{f} \cdot f
$$

\section{E. Copper loss}

The primary and secondary windings of the transformer and the inductor coil exhibit some resistance which causes a dissipation of energy in the form of heat. Using the information from previous sections, the needed expressions [18] can be easily attained.

$$
\begin{gathered}
P_{p}=R_{p}\left(\frac{I_{p}^{2}+I_{m}^{2}+I_{p} I_{m}}{3}\right)\left(\frac{T_{o n}}{T}\right) \\
P_{s}=R_{s}\left(\frac{I_{1}^{2}+I_{2}^{2}+I_{1} I_{2}}{6}\right) \\
P_{L}=R_{\text {coil }}\left(\frac{I_{1}^{2}+I_{2}^{2}+I_{1} I_{2}}{3}\right) .
\end{gathered}
$$

The values of $I_{m}, I_{p}, I_{1}, I_{2} \& \frac{T_{o n}}{T}$ can be found using the information in section A by (2), (3), (4), (6), and (7). In regards to small variations of temperature in the transformer and inductor windings, the temperature effect on the copper loss is neglected in this study. Skin effect refers to the tendency of current flow in a conductor to be confined to a layer in the conductor close to its outer surface. At low frequencies the skin effect is negligible and the distribution of current across the conductor is uniform. As the frequency is increased, the depth to which the flow can penetrate is reduced. In this paper, the designed converter works in medium frequency of up to $200 \mathrm{kHz}$, The effect of the frequency on the copper loss can also be neglected.

\section{F. Capacitor's ESR and ESL losses}

With an ideal capacitor, the insertion loss increases as the frequency becomes higher. However, with actual capacitors, the insertion loss increases until the frequency reaches a certain level (self-resonance frequency) and then the insertion 
loss decreases. The insertion loss of capacitors increase until the frequency reaches a self-resonance frequency and then decrease due to the residual inductance of the lead wires and the capacitor's electrode pattern existing in series with the capacitance. The residual inductance (ESL) varies depending on the type of capacitor. It can also vary in the same type of capacitor, depending on the dielectric material and the structure of the electrode pattern.

The second factor that causes deterioration in the characteristic of capacitors is the equivalent series resistance (ESR). The insertion loss will be lower due to the ESR caused by the electrode and the material. The ESR is very low in ceramic capacitors but higher in aluminum electrolytic capacitors. It is found that when the temperature of a capacitor rises, the ESR generally increases, though in a non-linear fashion. Increasing the frequency has a similar effect. In this paper the maximum switching frequency will be $200 \mathrm{kHz}$. As a result, the effect of the ESL will be neglected. Therefore. only the capacitor loss due to the ESR is considered in this paper. In view of the high levels of current, the ESR plays a major role in the performance of the circuit as a whole. Capacitors with high levels of ESR will naturally need to dissipate this power as heat. For some circuits that have only low values of current, such as the implemented circuit in this paper, this may not be a problem. As a result, the temperature effect on the output capacitance can also be ignored. The ESR value of a capacitor is seldom given by the manufacturer. However, the following rule-of-thumb relationship to calculate the ESR of electrolytic capacitors [8] can be used.

$$
E S R \times C=65 \times 10^{-6} .
$$

The DC component of the inductor current flows into the load, while its variations are compensated by the capacitor current. The consequent power loss would then be:

$$
P_{E S R}=E S R \times \frac{\left(I_{2}-I_{1}\right)^{2}}{12} .
$$

\section{G. Leakage current loss}

In the MOSFET off periods, there is some current leak from the drain to the source. This leakage current, together with the voltage appearing across the switch when it is open, will cause power loss. Equation (23) calculates the power loss associated with the leakage current.

$$
P_{\text {leak }}=\frac{1}{T} \int_{T_{\text {on }}}^{T} V_{\text {sw }}(t) I_{\text {leak }} d t=V_{\text {in }} I_{\text {leak }}
$$

In modern power MOSFETs however, the leakage current is very small and the power loss associated to it can be neglected.

\section{H. Core loss}

The magnetic cores present in a DC-DC converter (transformer and inductor) bring about a certain amount of power loss. This power loss can be expressed in terms of the core's weight or volume, operating frequency and flux density [13],[22].

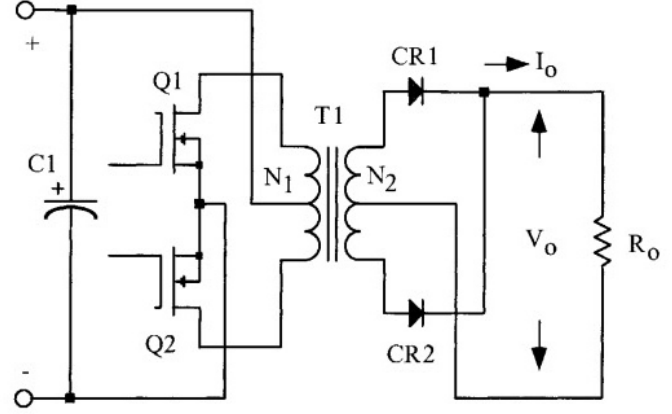

Fig. 4. Transformer in push-pull Converter.

$$
\begin{gathered}
P_{\text {core }}=k f^{m} B^{n}\left(\frac{W}{K g}\right) \quad \text { for ferrite cores } \\
P_{\text {core }}=\frac{f}{\frac{a}{B^{3}}+\frac{b}{B^{2.3}} \frac{c}{B^{1.65}}}+d f^{2} B^{2}
\end{gathered}
$$

for iron powder cores.

The constants in the above relationships are decided according to the particular core material and are given in [13] for various materials. The transformer and the output inductor operating flux density are driven in (26).

$$
B_{T}=\frac{V_{\text {in }} \times 10^{4}}{K_{f} N_{p} A_{c} f}, \quad B_{L}=\frac{\mu N I_{\text {Load }}}{l_{c}} .
$$

\section{Converter Weight And Size}

As stated previously, the exploitation of higher switching frequencies allows for the use of smaller and lighter components in the converter. The bulkiest components in a DC-DC converter are the isolating transformer, the output inductor and the output capacitor. In this section, the effect of the switching frequency on the size and weight of the transformer core are quantified. The output inductor and capacitor will also shrink as the switching frequency is increased (without letting the ripple exceed the maximum tolerable value.) However, since the overall weight and size of the converter is dominated by the transformer rather than the output inductor and capacitor, the transformer sizing becomes more important and a switching frequency which will minimize the transformer size is chosen. Then according to the chosen frequency, an appropriate inductor and capacitance to meet the maximum tolerable ripple specifications are selected. The size and weight of the selected inductor and capacitor can then be added to those of the transformer, resulting in an overall estimation of the converter size and weight.

Most often in transformer magnetic literature, the size and weight of a transformer are related to a parameter called the Area Product (Ap) which is the product of the core crosssectional area (Ac) and the window area (Wa) [22]. Fig. 4 shows the transformer in a push-pull DC-DC converter.

The volume occupied by a transformer and its weight are related to the area product by the two coefficients $K_{v}$ and $K_{w}$ as shown in the following relationships:

$$
V=K_{v} A_{p}^{0.75}
$$




$$
W=K_{w} A_{p}^{0.75} .
$$

The values of $K_{v}$ and $K_{w}$ are decided according to the particular core geometry used. Various tables are provided in [22],[25] which indicate these coefficients for different core geometries and dimensions.

The minimum needed area product is selected according to the power handling expectations of the core. The mathematical relationship is stated in the following equations [22]:

$$
\begin{gathered}
P_{t}=P_{\text {in }}+P_{\text {out }}, P_{\text {in }}=\frac{P_{o}}{\eta_{T}} \\
P_{\text {in }}=V_{P} I_{P}, P_{o}=V_{s} I_{s} \\
A_{p}=\frac{P_{t}\left(10^{4}\right)}{B_{a c} f J K_{f} K_{u}} \frac{\left(1+\frac{1}{\eta_{T}}\right) P_{\text {out }} \times 10^{4}}{B_{a c} f J K_{f} K_{u}}\left[\mathrm{~cm}^{4}\right] \\
P_{t}=2 \sqrt{2} P_{\text {in }} \text { in Push-Pull converter. }
\end{gathered}
$$

In the above equation $\eta_{T}$ is the transformer efficiency (which can be estimated using the information provided in section 2 for the transformer losses), $K_{f}$ is the waveform coefficient ( $K_{f}=4$ for square waves), $K_{u}$ is the window utilization factor (which shows what proportion of the window area is occupied by the windings), $B_{a c}$ is the maximum flux density in the core expressed in Gausses (selected according to the characteristics of the core material), $J$ is the current density of the wires (which should be tolerable by the chosen wire size at full load) and $f$ is the operating frequency in Hertz. The use of a thicker wire for the windings can decrease the current density of the wires for a particular load condition, but in return it occupies more space in the window and thus increases the value of $K_{u}$. Hence the product of $K_{u} \times J$ tends to be somewhat constant.

As can be seen in the equation, a smaller area product would result in a higher flux density in the core in order to generate the same amount of output power. Thus a failure to meet the above sizing requirement would result in core saturation and consequently the destruction of the converter. But since the area product is inversely proportional to the switching frequency, at higher frequencies a smaller core can deliver the same amount of power to the load without saturation.

\section{Output Voltage Ripple}

In the design procedure of any power supply, a maximum tolerable voltage ripple is often specified according to the particular application it is going to be used in. In space applications, generally space-qualified components are used. For example, electrolyte type capacitors cannot be used and another type of capacitor should be utilized in the designed circuits. The designer should make sure that the ripple does not exceed the specified value under any circumstances. There are two disparate components of the output ripple. One is due to the charging and discharging of output capacitance itself and the other is due to the current flowing into the capacitor's ESR. Both components will be calculated. These components are not in phase with each other, but for a conservative design, it is assumed that the total ripple is the sum of these two components.
TABLE I

THE DC-DC CONVERTER SPECIFICATIONS

\begin{tabular}{|l|l|}
\hline Output Voltage & $12 \mathrm{~V}$ \\
\hline Nominal Load Current & $4 \mathrm{~A}$ \\
\hline Input Voltage & $18 \mathrm{~V}-36 \mathrm{~V}$ \\
\hline Maximum allowable ripple & $100 \mathrm{mV}$ \\
\hline Transformer Core & EI-3530 \\
\hline Inductor Core & T106-52 Iron powder core \\
\hline
\end{tabular}

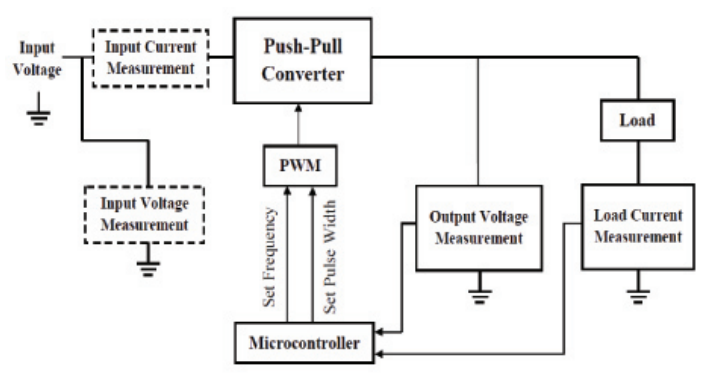

Fig. 5. Block diagram of the test bed.

$$
\begin{gathered}
V_{r-E S R}=E S R \times\left(I_{2}-I_{1}\right) \\
V_{r-\text { cap }}=\frac{\left(I_{2}-I_{1}\right)}{8 f C} .
\end{gathered}
$$

\section{IMPLEMENTATION}

In order to provide a test bed for the investigation of the proposed loss models and the output voltage ripple, a $12 \mathrm{~V} / 4 \mathrm{~A}$ push-pull DC-DC converter was designed and implemented. Push-pull topology is the best choice for investigating efficiency issues, since it exhibits all of the different types of power loss that are usually encountered in DC-DC converters. Detailed specifications of the implemented converter are provided in Table I.

The primary turns of the transformer was chosen in such a way that the flux density fluctuations in the EI-3530 ferrite core would not exceed $1000 \mathrm{G}$, ensuring that it will not saturate. Moreover, an appropriate selection of the inductor coil turns was made in order to prevent core saturation and current discontinuities in the inductor.

In the converter, the output voltage needs to be measured because the pulse width of the PWM signal is chosen according to the output voltage. Moreover, since this paper is particularly concerned with the efficiency of the converter, a more complete measurement system is required. Therefore, measuring circuits for the load current, the input current and the input voltage were designed and implemented on the board. An ATmega64 AVR microcontroller was utilized to sense these parameters and set the pulse width and the switching frequency of the converter based on them. The implemented system block diagram is shown in Fig. 5. In this paper, the aim is to evaluate a space dedicated DC-DC converter. It is well known that in order to cool a system/device in space applications heat sinks can not be used. However, in the implemented test bed heat sinks were used in order to avoid complexity.

\section{Modeling And Simulation}

The aforementioned equations were implemented in the MATLAB environment in order to simulate the sources of 
TABLE II

THE GATE-DRAIN CAPACITANCE DURING SWITCHING TIME

\begin{tabular}{|c|c|c|c|c|c|}
\hline \multirow{2}{*}{} & $\begin{array}{c}\text { Switch on } \\
\text { MOSFET Voltage }\end{array}$ & \multicolumn{4}{|c|}{ Switch off $1.3 \times\left(2 V_{c c}\right)=2.6 \times V_{\text {in }}$} \\
\cline { 2 - 6 } & $R_{D \text { Son }} \times I_{\text {on }} \approx 0$ & $46.8 \mathrm{~V}$ & $62.4 \mathrm{~V}$ & $78 \mathrm{~V}$ & 93.6 \\
\hline CGD & $1300 \mathrm{pf}$ & $60 \mathrm{pf}$ & $47 \mathrm{pf}$ & $28 \mathrm{pf}$ & $23 \mathrm{pf}$ \\
\hline
\end{tabular}

power loss and to define the frequency dependency of the output voltage ripple and the transformer volume in a $50 \mathrm{~W}$ push-pull DC-DC converter. As mentioned earlier, a detailed analysis and simulation was reported in [18] regarding all of the sources of power loss in a DC-DC converter. Here, a brief description regarding the necessary information, in order to simulate power loss of a DC-DC converter, is presented. Then, the frequency dependency of the output voltage ripple and the transformer volume are shown.

IRF540N, N-channel power MOSFETs where chosen as the primary switches in the push-pull DC-DC converter. From the datasheet, it can be seen that in the worst case, $R_{D S o n}=$ $0.04 \Omega$ at $25^{\circ} \mathrm{C}$ [23]. Using appropriate heat-sinks for the two switches, the measured MOSFETs' temperatures were approximately $60^{\circ} \mathrm{C}$ under the full load condition. Therefore, the resistance will be $R_{D S o n}\left(60^{\circ} \mathrm{C}\right) \approx 1.3 \times R_{D S o n}\left(25^{\circ} \mathrm{C}\right) \approx 0.052 \Omega$. Equation (8) relates the loss of an anti-parallel diode to the following characteristics [23]:

$U_{D 0} \approx 1 V, I_{S D}=I_{P}$ and $t_{D}=t_{d}(O F F)=40$ s.

Fig. 6 shows the MOSFET capacitances vs. the drain to source voltage which shows nonlinear variations with respect to the voltage [23]. In order to calculate the voltage fall and rise times during a switching period with reasonable accuracy, the non-linearity of the gate-drain capacitance has to be taken into account. Such a non-linearity, as shown in Fig. 6, cannot be easily incorporated into the calculations. Hence, two-point approximation is used. This would be a worst-case analysis for switching loss calculation [9]. In a push-pull DC-DC converter, the voltage stress over the switches is $1.3 \times\left(2 V_{c c}\right)$ during turnoff [8]. The input voltage is supposed to be provided from a solar array as in a satellite. The specified range is the typical output voltages produced by the solar array in satellites. It is worth mentioning that the input voltage variations of the converter are chosen to be in the range $[18 \mathrm{~V}, 36 \mathrm{~V}]$ and that the maximum load current is supposed to be 4A.

A curve fitting method was used in order to have an accurate estimation of the MOSFET switching loss. Equation (35) fits the gate-drain capacitance vs. the drain to the source voltage during the switching time, and it is used to define the capacitance utilized in the two-point approximation approach [9].

$C_{G D}=\frac{\left(p_{1} V_{D S}^{5}+p_{2} V_{D S}^{4}+p_{3} V_{D S}^{3}+p_{4} V_{D S}^{2}+p_{5} V_{D S}+p_{6}\right)}{\left(V_{D S}+q_{1}\right)} \times 10^{-12}$

where $\quad p_{1}=-9.736 \mathrm{e}-7, \quad p_{2}=0.0002133, \quad p_{3}=-0.01389$, $p_{4}=0.002949, p_{5}=31.91, p_{6}=1930$ and $q_{1}=1.447$.

The gate-drain capacitance variations can be seen in Table II during the switching time. These points are utilized in the two-point approximation approach.

As previously mentioned, Fig. 2 shows the MOSFET voltage and current waveforms during the on and off transitions.

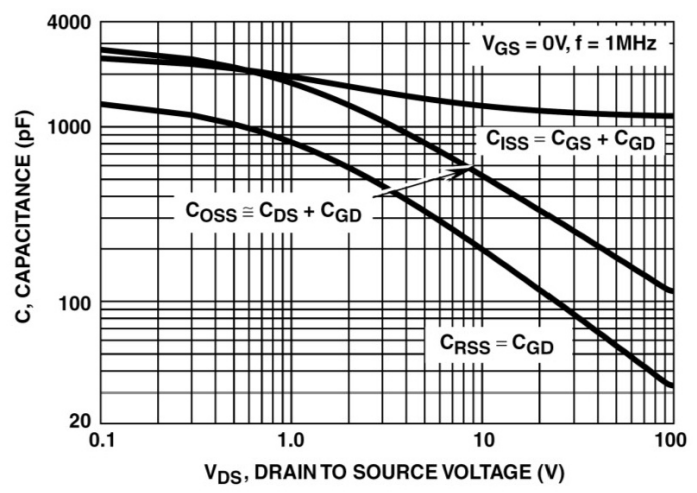

Fig. 6. The MOSFET capacitances voltage dependency.

The gate current during $t_{f u}$ can be calculated as:

$$
I_{\text {Gon }}=\frac{U_{D R}-U_{(\text {plateau })}}{R_{G}} .
$$

The voltage fall time can now be calculated as the median of the fall times defined through the gate current and the capacitances $C_{G D 1}$ and $C_{G D 2}$.

$$
\begin{gathered}
t f u=\frac{t f u 1+t f u 2}{2} \\
t f u 1=\left(U_{D D}-R_{D S o n} \cdot I_{D o n}\right) \frac{C_{G D 1}}{I_{G o n}} \\
t f u 2=\left(U_{D D}-R_{D S o n} \cdot I_{D o n}\right) \frac{C_{G D 2}}{I_{G o n}} .
\end{gathered}
$$

The gate current and the voltage rise time can be expressed as:

$$
\begin{gathered}
I_{\text {Goff }}=-\frac{U_{(\text {plateau })}}{R_{G}} \\
\text { tru }=\frac{\text { tru } 1+t r u 2}{2} \\
t r u 1=\left(U_{D D}-R_{D S o n} \cdot I_{D o n}\right) \frac{C_{G D 1}}{I_{o f f}} \\
t r u 2=\left(U_{D D}-R_{D S o n} \cdot I_{D o n}\right) \frac{C_{G D 2}}{I_{G o f f}} .
\end{gathered}
$$

Therefore, using Equations (9)-(13), the MOSFET switching loss can be determined. The MOSFET switching loss is shown in Fig. 7. A BYV32E dual ultra-fast rectifier diode was chosen as an output rectifier [24]. Equations (14) and (17) describe the conduction and switching losses of the output rectifier. Considering the wire diameter, length and material, the primary and secondary windings of the transformer and the inductor coil resistances are as follows: $R_{p}=R_{s}=0.0321 \Omega$ and Rcoil $=0.0481 \Omega$.

In order to measure the input current and to observe its behavior, a very low resistance $\left(R_{\text {Sense }}=0.04 \Omega\right)$ was series connected to the MOSFETs' source terminals. According to the converter design (test bed), a $1000 \mu \mathrm{F}$ electrolytic type output capacitor was chosen. Hence, by using Eq. (21) the output capacitance ESR will be: $E S R=0.065 \Omega$.

According to the datasheet of the IRF540N, the leakage current has a negligible value of $1 \mu \mathrm{A}$. Therefore, the MOSFET leakage power loss can be neglected in this paper. As 


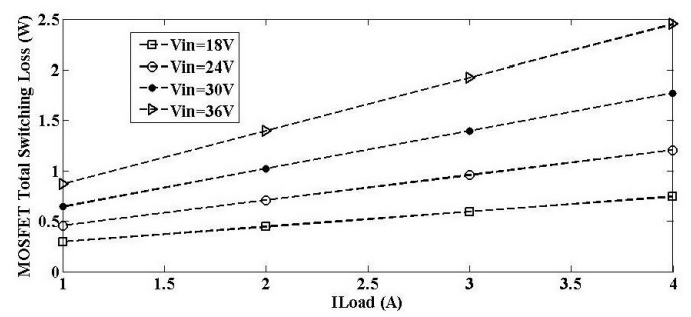

Fig. 7. MOSFET total switching loss.

TABLE III

THE CONSTANTS FOR THE FERRITE CORE LOSS

\begin{tabular}{|c|c|c|c|}
\hline PC40 Material & k & m & n \\
\hline$f<100 \mathrm{kHz}$ & $5.597 \times 10^{-4}$ & 1.43 & 2.85 \\
\hline $100 \mathrm{kHz} \leq f<500 \mathrm{kHz}$ & $4.316 \times 10^{-5}$ & 1.64 & 2.68 \\
\hline$f \geq 500 \mathrm{kHz}$ & $1.678 \times 10^{-6}$ & 1.84 & 2.28 \\
\hline
\end{tabular}

mentioned, the magnetic cores in the converter bring about a certain amount of power loss. An EI3530 with PC40 material was chosen as the ferrite core of the push-pull transformer [25]. Equation (24) determines the transformer core loss and Table III describes the required constants for equation [22].

The constants for the core loss equation are chosen based on the assigned switching frequency of the converter.

$$
P_{\text {core }}=5.597 \times 10^{-4} f^{1.43} B^{2.85}\left(\frac{W}{K g}\right)
$$

An iron powder core (T106-52) was used for the output inductor, for which the associated power loss is stated by Eq. (25). The coefficients for the core loss equation are as follows [13],[22]:

$$
\begin{gathered}
a=10^{-6}, b=6.94 \times 10^{-5}, c=5.27 \times 10^{-4} \& d=6.9 \\
P_{\text {core-Ind }}=\frac{f}{\frac{10^{-6}}{B^{3}}+\frac{6.94 \times 10^{-5}}{B^{2.3}} \frac{5.27 \times 10^{-4}}{B^{1.65}}}+6.9 f^{2} B^{2}
\end{gathered}
$$

Finally, Fig. 8 and 9 show the efficiency and power loss of the converter for various input voltages and load conditions and at a switching frequency of $60 \mathrm{kHz}$.

Figs. 10 and 11 also show the frequency dependency of the output voltage ripple and the transformer volume respectively.

\section{Selection of An Optimum Switching FREQUENCY FOR THE CONVERTER}

As previously discussed, in order to find the optimum switching frequency of a converter, a trade-off should be considered among the three effective parameters: the efficiency or power loss, the output voltage ripple, and the volume of the transformer. For this purpose, a cost function is proposed as follows. The main goal of this paper is to find the optimum frequency which optimizes the following function:

$$
\begin{gathered}
F_{\cos t}=w_{1} \operatorname{Loss}(f)+w_{2} \operatorname{Vr}(f)+w_{3} \operatorname{Vol}(f) \\
w_{1}+w_{2}+w_{3}=1
\end{gathered}
$$

where $w_{1}, w_{2}$ and $w_{3}$ are the assigned weight coefficients for the power loss, the output voltage ripple and the transformer volume respectively. At first, the three mentioned parameters (power loss, output voltage ripple, and volume of the transformer) are calculated from $20 \mathrm{kHz}$ to $200 \mathrm{kHz}$ with a $2 \mathrm{kHz}$

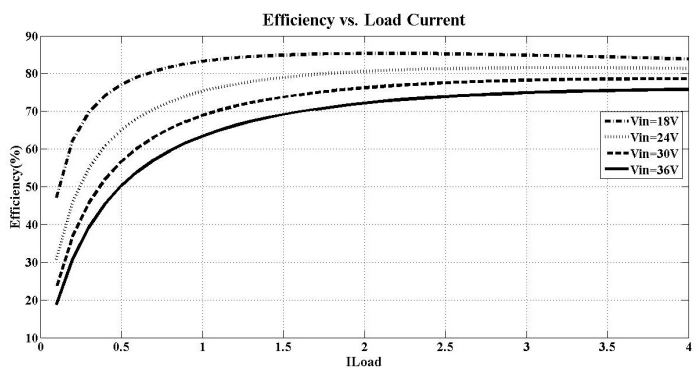

Fig. 8. The converter efficiency at $60 \mathrm{kHz}$

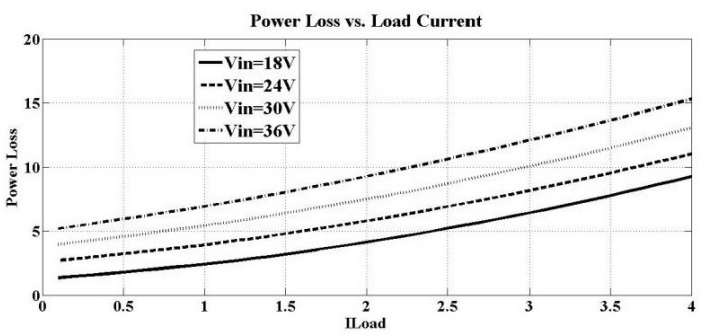

Fig. 9. The converter power loss at $60 \mathrm{kHz}$

step for any input voltage $(18 \mathrm{~V}<\mathrm{Vin}<36 \mathrm{~V})$ and load current $(0<$ ILoad $<4 \mathrm{~A})$. Then each parameter is normalized to its maximum value. As in (44) the normalized parameters are used. Therefore, a proportional weight function can be used. Fig. 12 shows a flowchart of the implemented algorithm.

There are also criterion for the evaluation of the three mentioned parameters which are selected according to the application. In most applications especially space or aerospace applications, these criterions will be defined at the level of system engineering. In this paper, it is assumed that the following values are defined by a system engineer as follows: $w_{1}=0.4 \pm 0.05, w_{2}=0.1 \pm 0.05$ and $w_{3}=0.5 \pm 0.05$ while $w_{1}+w_{1}+w_{1}=1$. Therefore, by optimization of the proposed cost function, an optimum frequency is determined based on the chosen weight functions. At first, the best weight functions should be defined in the specified ranges by a system engineer. Using the implemented algorithm (Fig. 12), the best weight functions in the above ranges are obtained as $w_{1}=0.35, w_{2}=0.15$, and $w_{3}=0.5$. Table IV shows the acquired optimum switching frequency (extracted from the algorithm) of the converter according to the optimal weight functions. Depending on the chosen coefficients, the optimum frequency is in the range of $126 \mathrm{kHz}$ and $202 \mathrm{kHz}$ for the above input voltages and load currents. Therefore, the controller should adjust the switching frequency of the DC-DC converter proportionally to the input voltage and the load current.

The optimized converter efficiency is provided in Table V. Table VI shows the minimum and maximum values of the output voltage ripple and the needed transformer volume in order to handle the required power in the range of the optimum

TABLE IV

THE OPTIMUM SWITCHING FREQUENCY OF THE CONVERTER

\begin{tabular}{|c|c|c|c|c|}
\hline $\mathrm{I}_{\text {Load }}$ & $18 \mathrm{~V}$ & $24 \mathrm{~V}$ & $30 \mathrm{~V}$ & $36 \mathrm{~V}$ \\
\hline $0.5 \mathrm{~A}$ & $170 \mathrm{kHz}$ & $202 \mathrm{kHz}$ & $202 \mathrm{kHz}$ & $202 \mathrm{kHz}$ \\
\hline $1.5 \mathrm{~A}$ & $146 \mathrm{kHz}$ & $162 \mathrm{kHz}$ & $162 \mathrm{kHz}$ & $160 \mathrm{kHz}$ \\
\hline $2.5 \mathrm{~A}$ & $144 \mathrm{kHz}$ & $144 \mathrm{kHz}$ & $140 \mathrm{kHz}$ & $136 \mathrm{kHz}$ \\
\hline $3.5 \mathrm{~A}$ & $152 \mathrm{kHz}$ & $140 \mathrm{kHz}$ & $132 \mathrm{kHz}$ & $126 \mathrm{kHz}$ \\
\hline
\end{tabular}




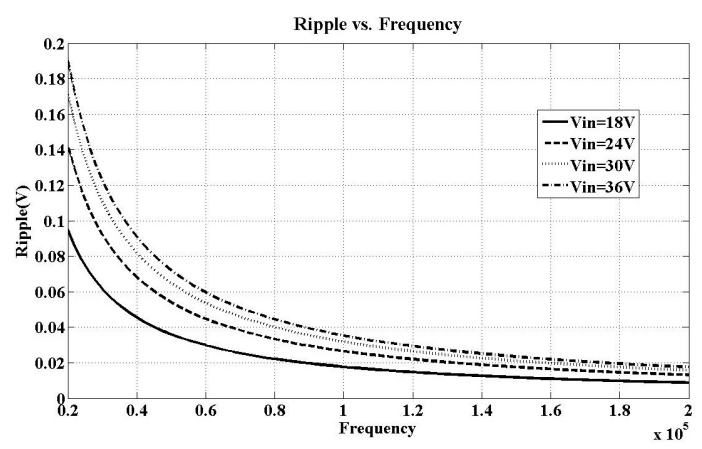

Fig. 10. The converter output voltage ripple

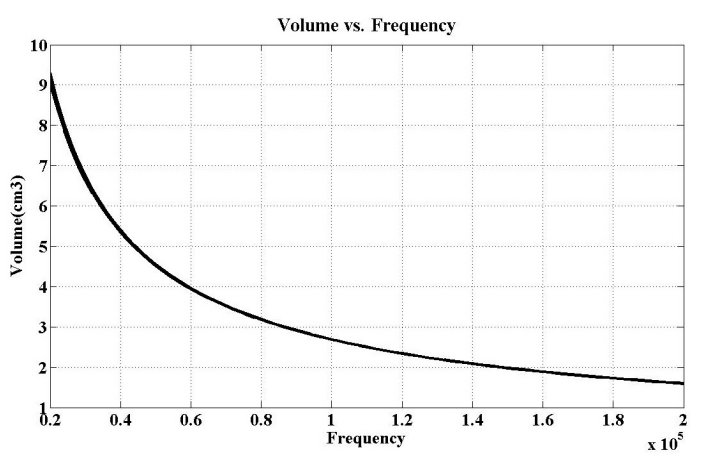

Fig. 11. The converter transformer volume

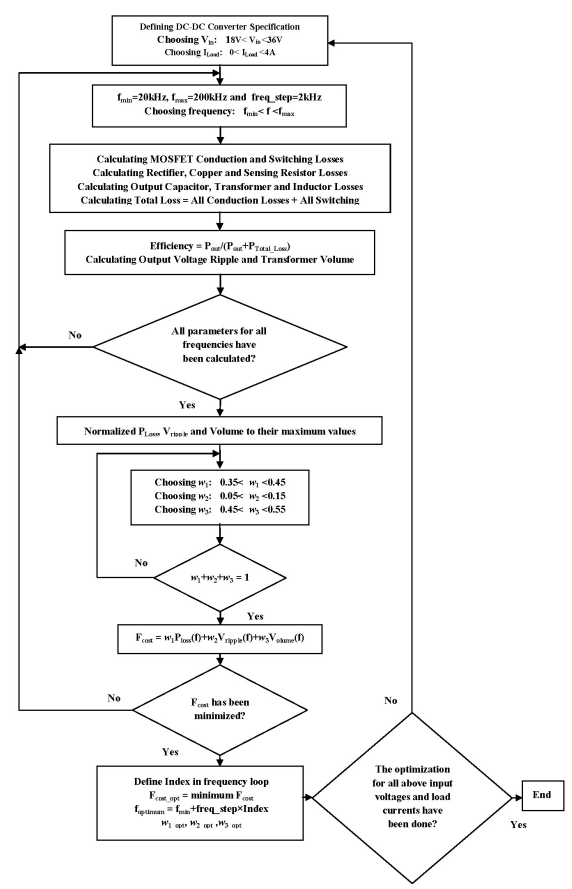

Fig. 12. Flowchart of the implemented algorithm

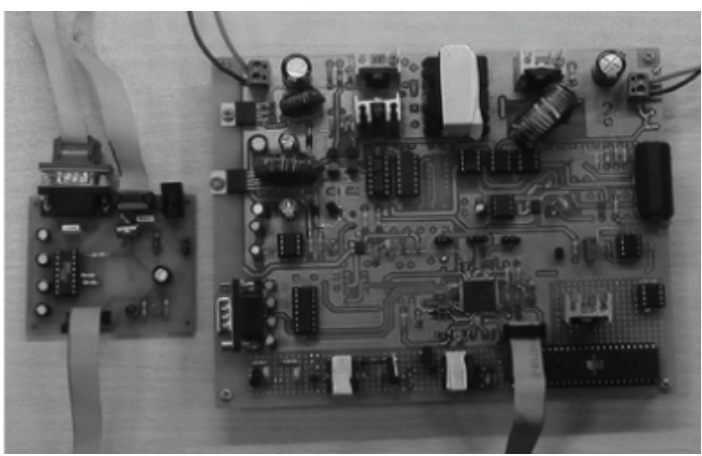

Fig. 13. The experimental setup

TABLE V

THE OPTIMIZED EFFICIENCY OF THE CONVERTER (\%)

\begin{tabular}{|c|c|c|c|c|}
\hline $\mathrm{I}_{\text {Load }}$ & $18 \mathrm{~V}$ & $24 \mathrm{~V}$ & $30 \mathrm{~V}$ & $36 \mathrm{~V}$ \\
\hline $0.5 \mathrm{~A}$ & 76.4 & 66.1 & 58.5 & 52.4 \\
\hline $1.5 \mathrm{~A}$ & 83.7 & 78 & 72.8 & 68.1 \\
\hline $2.5 \mathrm{~A}$ & 83.8 & 80 & 76.1 & 72.1 \\
\hline $3.5 \mathrm{~A}$ & 82.8 & 80 & 76.8 & 73.6 \\
\hline
\end{tabular}

frequency.

As previously mentioned, a EI3530 transformer was utilized in the test bed, whose volume is $8.35 \mathrm{~cm}^{3}$, but the maximum required transformer volume is $2.5802 \mathrm{~cm}^{3}$ as shown in Table VI. Therefore, the size of the utilized transformer can be decreased. From [25], it can be seen that the EI28 transformer with PC40 material has a volume of $4.145 \mathrm{~cm}^{3}$ and thus it can be used.

Fig. 13 shows the experimental setup for this study. A new transformer with the previously designed winding turns was wrapped and used in the implemented test bed. The experimental data show that the designed system can handle the $50 \mathrm{~W}$ of output power in the acquired optimum frequency range without any problems. Finally, based on the proposed weight functions, the transformer volume can be decreased by up to $51 \%$.

\section{CONCLUSION}

In this paper, power loss models for all of the relevant components in a push-pull DC-DC converter, the frequency dependency of the output voltage ripple and the transformer volume were fully developed. A novel model, obtained from curve fitting method, was used to express the MOSFET gatedrain capacitance in order to estimate the MOSFET switching loss with greater accuracy. The proposed models are verified with a 50W push-pull DC-DC converter that was designed and implemented as a test bed. Data from experiments confirmed the simulation results and the converter's power loss and output voltage ripple can be estimated with adequate precision. Since the emphasis of this paper is on DC-DC converters in space applications, a trade-off between the power loss, the output voltage ripple and the utilized transformer volume of the converter was considered. Hence, a novel cost function

TABLE VI

The MAXimum VALUES OF VRIPPLE AND $A_{p}$

\begin{tabular}{|c|c|c|}
\hline & Min & Max \\
\hline $\mathrm{V}_{\text {ripple }}(\mathrm{V})$ & 0.0122 & 0.0333 \\
\hline Volume $\left(\mathrm{cm}^{3}\right)$ & 2.0363 & 2.5802 \\
\hline
\end{tabular}


with three weight functions was proposed in order to optimize the converter according to its application. An application in which the transformer volume has the highest priority in comparison with the converter power loss and the output voltage ripple was then evaluated. The obtained results, supported by experiments, show that the transformer volume can be decreased by up to $51 \%$. The developed models and algorithms in this paper can be used for other DC-DC converter topologies with little modification.

\section{APPENDIX}

\begin{tabular}{|c|c|}
\hline Symbol & Quantity \\
\hline$P_{M o s-C o n}$ & $\begin{array}{l}\text { MOSFET Conduction power } \\
\text { loss }\end{array}$ \\
\hline$T$ & Switching period \\
\hline$R_{D S o n}$ & Drain-Source on resistance \\
\hline$I_{s w}$ & Switch current \\
\hline$I_{P}$ & $\begin{array}{l}\text { Peak switch current during on } \\
\text { state }\end{array}$ \\
\hline$I_{m}$ & $\begin{array}{l}\text { Minimum switch current during } \\
\text { on state }\end{array}$ \\
\hline$T_{o n}$ & Switch on-time in each period \\
\hline$V_{\text {out }}$ & Output voltage \\
\hline$N_{p}$ & transformer's Primary winding \\
\hline$N_{s}$ & $\begin{array}{l}\text { transformer's secondary wind- } \\
\text { ing turns }\end{array}$ \\
\hline$V_{\text {in }}$ & Input voltage \\
\hline$I_{1}$ & Minimum load current \\
\hline$I_{2}$ & Maximum load current \\
\hline$I_{\text {magnetizing }}$ & Magnetizing current \\
\hline$L_{m}$ & Magnetizing inductance \\
\hline$f$ & Switching frequency \\
\hline$L$ & Output inductance \\
\hline$I_{\text {Load }}$ & Load current \\
\hline$P_{\text {Diode }}$ & $\begin{array}{l}\text { MOSFET's body diode power } \\
\text { loss }\end{array}$ \\
\hline$U_{D 0}$ & Diode's forward voltage drop \\
\hline$I_{S D}$ & Diode forward current \\
\hline$t_{D}$ & Body diode's on time \\
\hline$T_{J}$ & Junction temperature \\
\hline$E_{\text {onM }}$ & MOSFET turn-on energy loss \\
\hline$U_{D D}$ & MOSFET's supply voltage \\
\hline$I_{\text {Don }}$ & Minimum switch current during \\
\hline$t_{r i}$ & $\begin{array}{l}\text { on state } \\
\text { MOSFET's current rise-time }\end{array}$ \\
\hline$t_{f u}$ & MOSFET voltage fall-time \\
\hline$Q_{r r-M o s}$ & $\begin{array}{l}\text { MOSFET's reverse recovery } \\
\text { charge }\end{array}$ \\
\hline$E_{\text {onD }}$ & Body diode's turn-on energy \\
\hline$U_{D r r}$ & $\begin{array}{l}\text { loss } \\
\text { Diode's voltage during reverse } \\
\text { recovery }\end{array}$ \\
\hline$E_{o f f D}$ & Diode's turn-off energy loss \\
\hline$E_{o f f M}$ & MOSFET's turn-off energy loss \\
\hline$I_{D o f f}$ & $\begin{array}{l}\text { Peak switch current during on } \\
\text { state }\end{array}$ \\
\hline$t_{r u}$ & MOSFET's voltage rise-time \\
\hline$t_{f i}$ & MOSFET current fall-time \\
\hline
\end{tabular}

$P_{s w M}$
$P_{S w D}$
$P_{\text {diode-con }}$
$V_{F}$
$I_{D}$
$Q_{r r}$
$Q_{s}$
$Q_{f}$

$s$ $I_{R M}$

$d i / d t$ $t_{f}$ $V_{R}$ $P_{P}$

$R_{p}$

$P_{S}$

$R_{S}$

$P_{L}$

$R_{\text {coil }}$

$E S R$

$\mathrm{V} \quad$ ESR

V

A

A

A

$\mathrm{H}$

$\mathrm{Hz}$

$\mathrm{H}$

A

W

V

A

$\sec$

${ }^{\circ} \mathrm{C}$

$\mathrm{J}$

$\mathrm{V}$

A

$\sec$

$\sec$

C

J

$\mathrm{V}$

$\mathrm{J}$

$\mathrm{J}$

A

$\sec$

sec
MOSFET switching loss W

Body diode's switching loss W

Diode rectifier conduction loss W

Diode rectifier forward voltage $\mathrm{V}$

drop

Diode rectifier current A

Diode rectifier's reverse recov- $\mathrm{C}$

ery charge

Rectifier stored charge $\mathrm{C}$

effective capacitance charge of $\mathrm{C}$

rectifier

Diode rectifier softness factor

Diode rectifier's peak reverse

current

Rectifier current derivative A/S

Rectifier's reverse recovery sec

time

Diode's blocking voltage V

Primary winding copper loss W

Primary winding resistance $\quad \Omega$

Secondary winding copper loss $\mathrm{W}$

Secondary winding resistance $\Omega$

Inductor copper loss $\mathrm{W}$

Inductor resistance $\Omega$

Capacitor's equivalent series re- $\Omega$

$C \quad$ Output capacitance $\quad$ F

PESR ESR power loss W

$P_{\text {leak }} \quad$ MOSFET leakage loss W

$V_{s w} \quad$ MOSFET's off voltage V

Ileak MOSFET leakage current A

Pcore Transformer core loss W

$k \quad$ Coefficient for core loss equa-

tion

Flux density

Tesla

Coefficient for inductor core

loss equation

Coefficient for inductor core

loss equation

Coefficient for inductor core

loss equation

Coefficient for inductor core

loss equation

Transformer Flux density Tesla

Waveform coefficient

Transformer core area

Inductor flux density

Permeability

Inductor winding turns

Inductor's total path length m

Transformer volume $\quad \mathrm{cm}^{3}$

Volume coefficient

Area product

Transformer weight

Weight coefficient

Transformer apparent power W

Transformer primary power W

Transformer secondary power W

Transformer efficiency $\%$

Transformer primary voltage $\mathrm{V}$ 


\begin{tabular}{lll}
$I_{P}$ & Transformer primary current & $\mathrm{A}$ \\
$V_{S}$ & Transformer secondary voltage & $\mathrm{V}$ \\
$I_{S}$ & Transformer secondary current & $\mathrm{A}$ \\
$B_{a c}$ & Operating flux density & Tesla \\
$J$ & Current density & $\mathrm{A} / \mathrm{cm}^{2}$ \\
$K_{u}$ & Window utilization factor & - \\
$V_{r-E S R}$ & ESR ripple voltage & $\mathrm{V}$ \\
$V_{r-\text { cap }}$ & Capacitance ripple voltage & $\mathrm{V}$ \\
\hline
\end{tabular}

\section{REFERENCES}

[1] B. J. Masserant, E. W. Beans, and T. A. Stuart, "A study of volume versus frequency for soft switching igbt converters," IEEE Trans. Aerospace and Electronic Syst., Vol. 31, No. 1 pp. 280-287, Jan. 1995.

[2] J. W. Kolar, U. Drofenik, J. Biela, M. L. Heldwein, H. Ertl, T. Friedli, and S. D. Round, "PWM converter power density barriers" IEEJ Transactions on Industry Applications, Vol. 128, No. 4, pp. 468-480, 2008.

[3] J. Betten and M. Day, "Optimizing the switching frequency of ADSL power supplies," Analog Applications Journal, Texas Instruments Incorporated, pp. 23-27, 2002.

[4] M. Vasi, S.D. Round, J. Biela, and J.W. Kolar, "Mission Profile Based Optimization of a Synchronous-Buck DC-DC Converter for a Wearable Power System," in Proc. of the IEEE International Power Electronics and Motion (IPEMC), pp. 1384-1389, May 2009.

[5] Al-Hoor, W. Abu-Qahouq, J. A. Huang, L. Mikhael, and W. B. Batarseh, I., "Adaptive digital controller and design considerations for a variable switching frequency voltage regulator," IEEE Trans. Power Electron., Vol. 24, No. 11, pp. 2589-2602, Nov. 2009.

[6] D. Damasceno, L. Schuch, and J. R. Pinheiro, "Design procedure to minimize boost pfc volume concerning the trade-offs among switching frequency, input current ripple and soft-switching," in Proc. of the IEEE Power Electronics Specialists Conference, Vol. 3, pp. 2333-2338, 2005.

[7] S. Farhangi and A. S. Akmnal, "A simple and efficient optimization routine for design of high frequency power transformers," in Proceeding of 8th European Conference on Power Electronics and Applications, Lausanne, 1999.

[8] A.I. Pressman, K. Billings, and T. Morey, Switching power supply design, McGraw-Hill, Inc., 3rd Edition, 2009.

[9] D. Graovac, M. Purschel , A. Kiep, "MOSFET power losses calculation using the data-sheet parameters," Application Note, Vol. 1.1, Jul. 2006.

[10] Power Management \& Supply, "Improving efficiency of synchronous rectification by analysis of the mosfet power loss mechanism," Application Note, Rev. 2.0, Jun. 2009.

[11] J. Chen, J. Zhu, and Y. Guo, "Calculation of Power loss in output diode of a flyback switching dc-dc converter," in Proc. of International Power Electronics and Motion Control Conference, Vol. 1, pp. 1-5, 2006.

[12] J. Schonberger, and G. Feix, "Modeling turn-off losses in power diode," in Proceeding of 11th Workshop on Control and Modeling for Power Electronics, COMPEL, 2008.

[13] C. Oliver, "A new core loss model," Switching Power Magazine, Micrometals, Inc., pp. 1-3, Spring 2006.

[14] N. Garcia, "Determining Inductor Power Losses," Coilcraft, 2009.

[15] T. Eichhorn, "Estimate inductor losses easily in power supply designs," Power Electronic Technology, www.powerelectronics.com, 2005.

[16] Maxim Integrated Products, "An efficiency primer for switch-mode dcdc converter power supplies," Application Note 4266: www.maximic.com/an4266, 2008.

[17] D. Finn, G. Walker, and P. Sernia, "Method of extracting switching loss from a high efficiency mosfet based half bridge converter,"

[18] M. Taherbaneh, A.H Rezaie, H. GhafooriFard, M.B Menhaj, M. Mirsamadi, "Power loss analysis for efficiency estimation of a dc-dc converter," ICICE Trans. Electron., Vol. E94-C, No. 2, pp. 220-230, Feb. 2011.

[19] P. Markowski, "Estimating MOSFET switching losses means higher performance buck converters," PlanetAnalog.com, Dec. 2002.

[20] J. Shen, Z. Y. Xiong, X. Cheng, Y. F. Kumar, "Power MOSFET switching loss analysis: a new insight," in Proceeding of IEEE Industry Application Conference, Vol. 3, pp. 1438-1442, 2006.

[21] International IOR Rectifier, "A more realistic characterization of power mosfet output capacitance coss," Application Note AN-1001.
[22] W.T. Mclyman, Transformer and inductor design handbook, Third Edition, Kg Magnetics, Inc., USA 2004.

[23] Fairchild Semiconductor, "IRF540N Datasheet," Jan. 2002, http://www.datasheetcatalog.com.

[24] Philips Semiconductor, "BYV32E Datasheet,", Jul. 1998.

[25] Peian Electronic Manufacturing Inc., "EI-Type Cores," http://www.peianpeian.com.

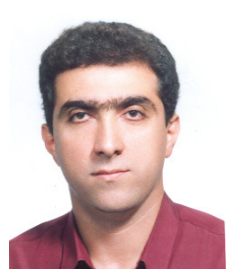

Mohsen Taherbaneh received his Ph.D. in Electrical Engineering from the Amirkabir University of Technology, Iran, in 2010. Since 1995, he has been working as a Researcher in the Department of Electrical and Information Technology of the Iranian Research Organization for Science and Technology, Tehran, Iran. His main interests include photovoltaic applications, satellite power subsystems, the study of solar cells, and power electronics. His research activity is focused on intelligent systems for power electronics, space-qualified subsystems and photovoltaic system design.

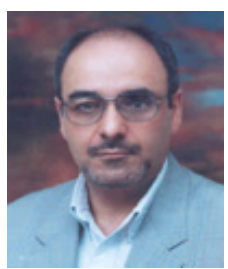

Amir H. Rezaie graduated with a degree in Electrical Engineering from the Amirkabir University of Technology, Iran, in 1983 and he received his Ph.D. in Engineering from Bristol University, England, in 1988. Since 1988, he has been working as a Lecturer and as the Head of the AIMS Research Lab in the Electrical Engineering Department of the Amirkabir University of Technology, Tehran, Iran. His main interests include the fields of automation, digital design and wireless sensor networks. He has supervised many projects such as radar based vehicle speed measurement systems, intelligent monitoring systems, photovoltaic applications, heat cost allocation systems, building management systems, object tracking, motion detection and simulators. He is also the author and co-author of two books in Persian and many technical papers.

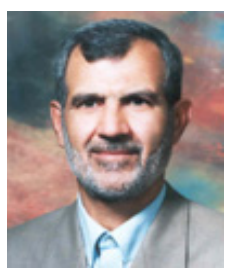

Hasan Ghafoorifard received his Ph.D. in Electrical Engineering from Kansas University in 1977. Since 1980, he has been with the Department of Electrical Engineering of the Amirkabir University of Technology, Tehran, Iran. He is an Associate Professor in the Department of Electrical Engineering of the Amirkabir University of Technology. His research interests include electronics as well as wave, electromagnetic and quantum mechanics. His research activity is focused on electromagnetism, quantum electronics, photovoltaic applications and the physics of solar cells.

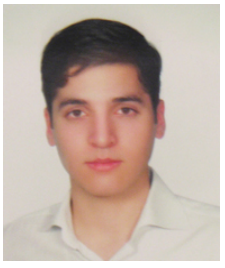

Maddad Mirsamadi is a MSC student in the Electrical Engineering Department of the Amirkabir University of Technology, Tehran, Iran. His research interests include power electronics theory and applications, energy conversion, photovoltaic and renewable energy.

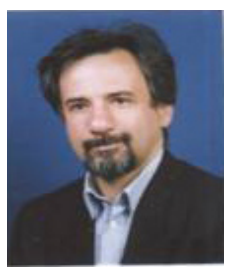

Mohammad B. Menhaj was born in Iran in 1959. He received his M.S. and Ph.D. in Electrical Engineering from the Ohio State University, USA, in 1989 and 1992 , respectively. In 1993, he joined the Amirkabir University of Technology, Tehran, Iran, where he is a Professor in the Department of Electrical Engineering. He is the author and co-author of more than 350 technical papers. $\mathrm{He}$ is also the author of three books: Computational Intelligence (vol. 1), Fundamentals of Neural Networks (Professor Hesabi Center of Publishing, Tehran, 1998 and Amirkabir University, Tehran, 2000) and Application of Computational Intelligence in Control (vol. 1) (Professor Hesabi Center of Publishing, Tehran, 1998), all in Persian. His main research interests lie in the theory of computational intelligence, adaptive systems and their applications in pattern recognition, control systems, power systems and communications. His research activity is focused on intelligent system design, photovoltaic applications and control theory. 